\title{
Pemanfaatan Listrik Tenaga Surya Sebagai Pasokan Listrik Untuk Menghidupkan Lampu PJU Lapangan Sarana Olah Raga Masyarakat Warga RT 002/05 BTN Cantiga Petir Cipondoh Tangerang
}

\author{
Retno Aita Diantari ${ }^{1}$; Heri Suyanto ${ }^{2}$; Tri Joko Pramono ${ }^{3}$; Syarif Hidayat ${ }^{4}$ \\ ${ }^{1,2,3,4}$ Institut Teknologi PLN \\ ${ }^{1}$ retno.aita@itpln.ac.id
}

\begin{abstract}
This article was prepared based on the Community Service Institute (PKM) of the 2019 PLN Institute of Technology which was carried out in the field of sports facilities for residents of RT002 I 05 BTN Cantiga Petir Cipondoh Tangerang with problems of frequent illegal connection or theft of electricity from electric poles for street lighting and there are still locations that require street lighting. The Purpose of Community Service Activities (PKM) This is so that the public can know the use of Solar Electricity for the community and as an implementation with theory and practice is applied to the public about the development of solar electricity technology in current energy. Through this activity, the community of Cipondoh Lightning Cantiga residents learned about the use of solar electricity for the surrounding community to turn on the PJU Lights in the RT 002/05 BTN Cantiga Petir Cipondoh Tangerang Sports Field.
\end{abstract}

Keywords: PJU lights, Solar System, Utilization. Implementation

\begin{abstract}
ABSTRAK
Artikel ini disusun berdasarkan Kegiatan Pengabdian Kepada Masyarakat (PKM) Institut Teknologi PLN Tahun 2019 yang dilaksanakan di lapangan sarana olah raga masyarakat warga RT002/05 BTN Cantiga Petir Cipondoh Tangerang dengan permasalahan sering terjadi penyambungan liar atau pencurian listrik dari tiang listrik untuk penerangan lampu jalan dan masih terdapat lokasi membutuhkan penerangan jalan. Tujuan Kegiatan Pengabdian Kepada Masyarakat (PKM) ini Agar masyarakat dapat mengetahui pemanfaatan Listrik Tenaga Surya untuk untuk masyarakat dan sebagai implementasi dengan teori dan praktek di aplikasikan kepada masyarakat tentang perkembangan teknologi listrik tenaga surya pada energi saat ini. Melalui kegiatan ini di lingkungan Masyarakat warga Cantiga Petir Cipondoh mengetahui tentang pemanfaatan listrik tenaga surya bagi masyarakat sekitarnya untuk menghidupkan Lampu PJU di Lapangan Olah Raga Warga RT 002/05 BTN Cantiga Petir Cipondoh Tangerang.
\end{abstract}

Kata kunci: lampu PJU, listrik tenaga surya, pemanfaatan, implementasi 


\section{PENDAHULUAN}

\subsection{Latar Belakang}

Artikel ini disusun berdasarkan Kegiatan Pengabdian Kepada Masyarakat (PKM) Institut Teknologi PLN Tahun 2019 yang dilaksanakan di lapangan sarana olah raga masyarakat warga RT002/05 BTN Cantiga Petir Cipondoh Tangerang. Permasalahan yang sedang dihadapi oleh mitra adalah sering terjadi penyambungan liar seperti foto - foto dibawah ini. pada tiang listrik oleh PLN sehingga masyarakat untuk mendapatkan listrik untuk penerangan jalan umun sumber listrik yang tidak jelas dan dapat membahayakan Instalasi listrik liar pada Lampu PJU di sekitar lapangan Olah Raga. Dengan adanya kegiatan ini bisa membantu masyarakat untuk mengembangkan teknologi tenaga surya dalam hal ini untuk lampu PJU sarana olah raga masyarakat RT002/05 Petir dan Cipondoh Tangerang Banten.
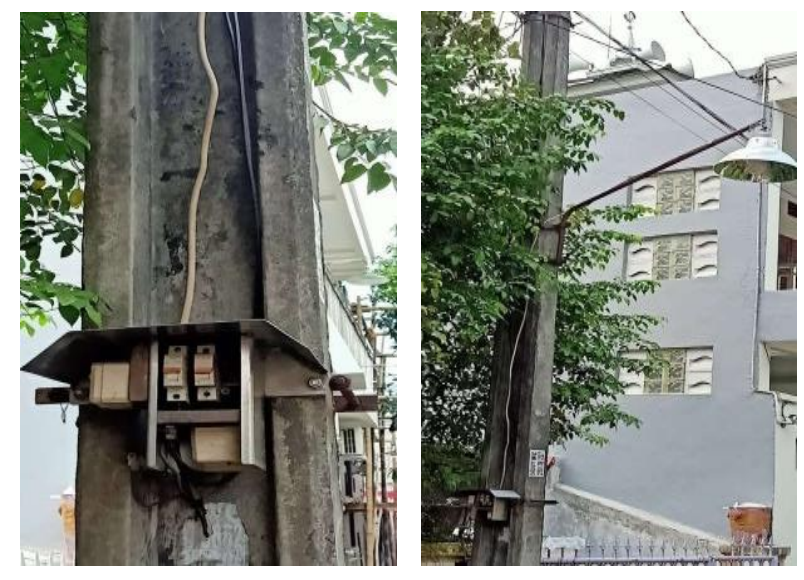

Gambar 1. Penyambungan Liar Untuk Lampu PJU Lapangan
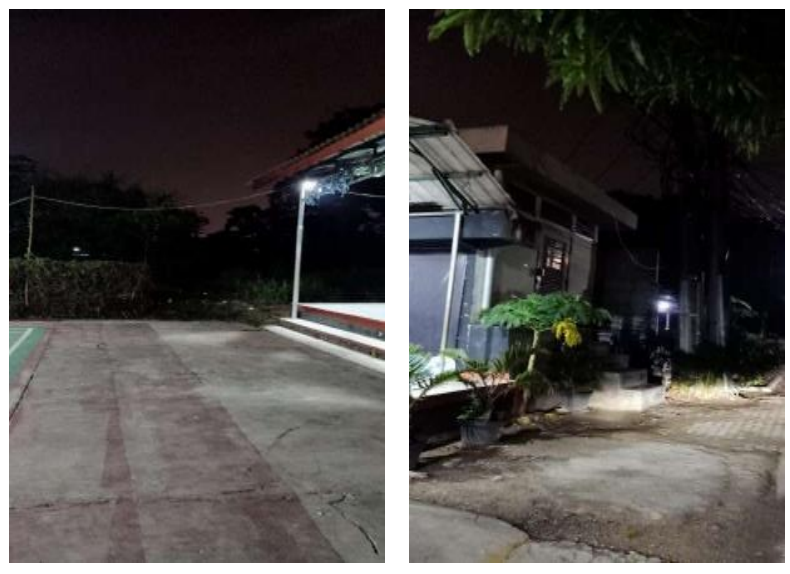

Gambar 2. Kondisi sekitar lapangan yang masih membutuhkan

Penerangan Dipilihnya lampu PJU berbasis solar system dikarenakan untuk mendukung program pemerintah penggunaan energi baru dan terbarukan (EBT) berupa tenaga surya merupakan salah satu prinsip untuk mencapai tujuan utama Kebijakan Energi Nasional (KEN) 2050 yakni Kemandirian dan Ketahanan Energi Nasional. Selain itu, jika menggunakan lampu PJU bersumber listrik PLN maka akan berdampak terhadap tagihan rekening listrik lampu PJU Pemerintah Daerah.

Tujuan Kegiatan Pengabdian Kepada Masyarakat (PKM) ini Agar masyarakat dapat mengetahui pemanfaatan Listrik Tenaga Surya untuk untuk masyarakat dan sebagai implementasi 
dengan teori dan praktek di aplikasikan kepada masyarakat tentang perkembangan teknologi listrik tenaga surya pada energi saat ini. Melalui kegiatan ini di lingkungan Masyarakat warga Cantiga Petir Cipondoh mengetahui tentang pemanfaatan listrik tenaga surya bagi masyarakat sekitarnya untuk menghidupkan Lampu PJU di Lapangan Olah Raga Warga RT 002/05 BTN Cantiga Petir Cipondoh Tangerang. Selain itu untuk tim Pengabdian Kepada Masyarakat (PKM) Institut Teknologi PLN yaitu dapat mempraktikkan ilmu dan keterampilan yang dimiliki, khususnya dalam bidang ketenagalistrikan melalui kegiatan sosialisasi dan implementasi pemasangan Pembangkit Listrik Tenaga Surya untuk di Masyarakat.

\section{METODE}

Berikut diagram alur Kegiatan Pengabdian Kepada Masyarakat (PKM)

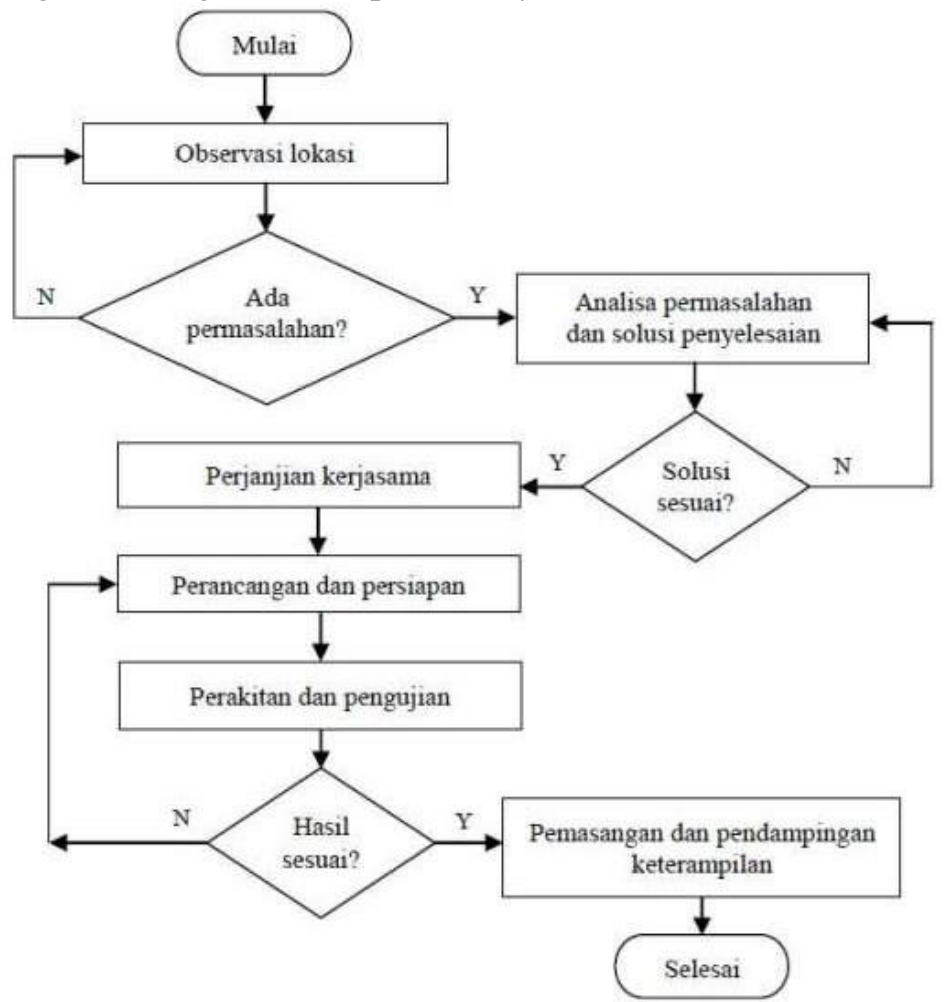

Gambar 3. Diagram Alur Kegiatan Pengabdian Masyarakat (PKM)

Langkah pertama melakukan observasi lokasi dengan hasil sesuai pada gambar 1 dan gambar 2 dengan permasalahan penyambungan listrik liar untuk lampu PJU dan masih terdapat lokasi sekitarnya membutuhkan penerangan.

Langkah kedua diskusi antara tim Pengabdian Kepada Masyarakat (PKM) dengan ketua RT atau perwakilan warga untuk mencari solusi permasalahan dengan hasil nya menemukan 6 (enam) titik lokasi yang akan dipasang Lampu PJU di Lapangan Olah Raga Warga RT 002/05 BTN Cantiga Petir Cipondoh Tangerang.

Langkah ketiga tim PKM membuat analisa dari permasalahan dan solusi penyelesaian untuk di diskusi dengan tim Pengabdian Kepada Masyarakat (PKM) untuk menentukan jadwal hari dan jam berapa pengabdian kepada masyarakat yang akan dilaksanakan untuk membuat perancangan dan persiapan apa saja yang di lakukan.

Langkah keempat Tim Pengabdian Kepada Masyarakat (PKM) Institut Teknologi PLN melakukan kerja sama dengan perwakilan warga setempat baik RT maupun RW dengan membuat perancangan 
dan persiapan yang akan di pasang lampu PJU tenaga surya seperti pembuatan dan perakitan lampu pju berbasic tenaga surya. Proses pembuatan dan perakitan lampu PJU berbasis solar system seperti ditunjukkan dalam Gambar 7. Kegiatan diawali dengan pembuatan tiang lampu PJU berbasis solar system. Tiang lampu yang telah selesai dibuat, selanjutnya dilengkapi dengan box panel, holder panel surya, dan instalasi kabel listrik. Pemasangan panel surya, charge control, battery, dan lampu dc dilakukan setelah tiang dipasang di titik lokasi pemasangan.

Langkah kelima Tim Pengabdian Kepada Masyarakat (PKM) Institut Teknologi PLN melakukan pengujian Lampu PJU tenaga surya Kegiatan pengujian komponen-komponen dilakukan dengan cara mensimulasi kondisi siang dan kondisi malam hari terhadap rangkaian komponen lampu PJU berbasis solar system. Gambar 8 menunjukkan pengujian komponen-komponen lampu PJU. Simulasi siang hari adalah dengan membiarkan panel surya terkena sinar matahari, sedangkan simulasi malam hari adalah dengan menutup bagian panel surya. Berdasarkan Gambar 4 terlihat bahwa pada kondisi siang hari lampu dc tidak menyala, sedangkan ketika kondisi malam hari lampu dc menyala. Interval waktu antara proses $O N$-OFF, dan proses $O F F-O N$ lampu PJU adalah berkisar 5 menit. Hasil pengujian ini menunjukkan bahwa komponen, dan proses otomatisasi berfungsi dengan baik.
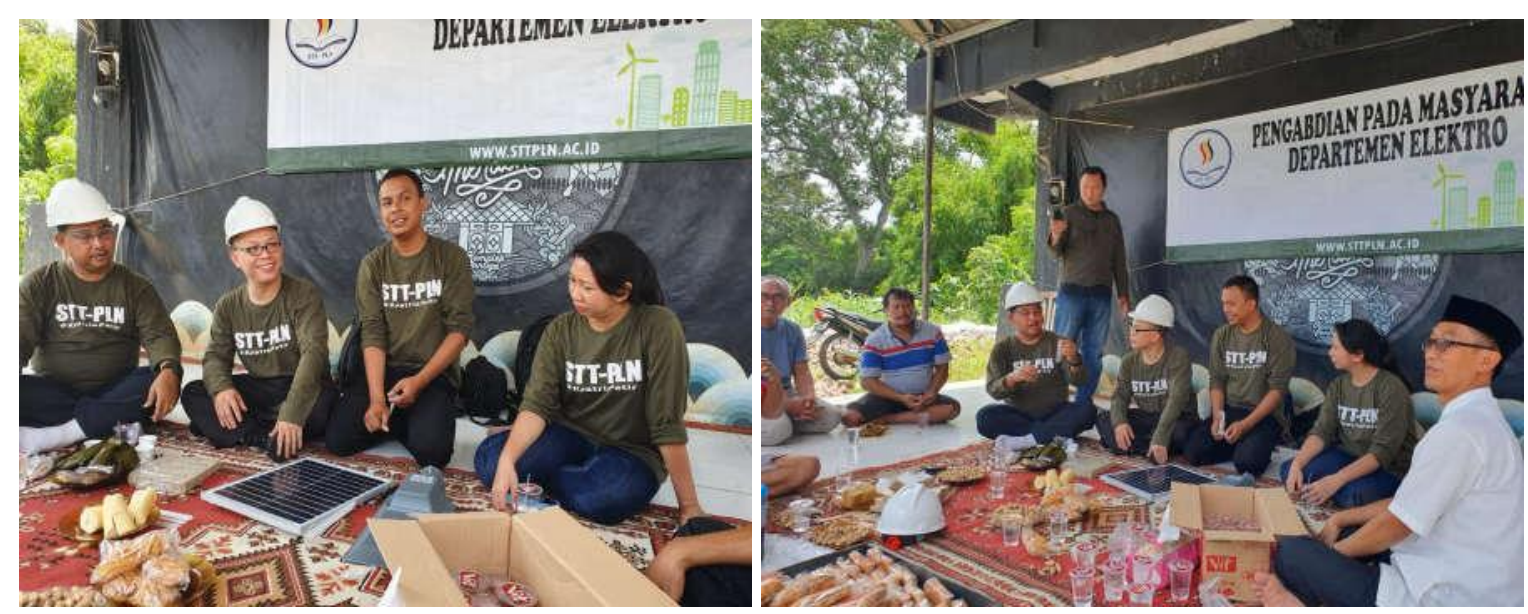

Gambar 4. Diskusi Tim Pengabdian Masyarakat (PKM) dengan Warga setempat
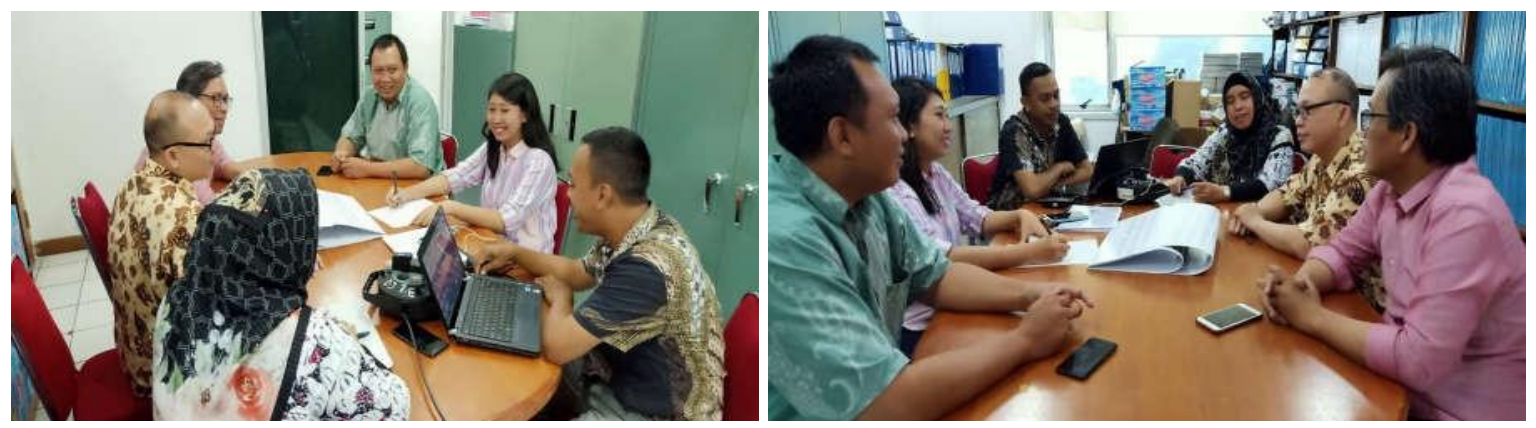

Gambar 5. Diskusi Internal antara Tim Pengabdian Masyarakat (PKM)

\section{Hasil dan Pembahasan}

Lampu PJU berbasis solar system yang akan dipasang di Lampu PJU di Lapangan Olah Raga Warga RT 002/05 BTN Cantiga Petir Cipondoh Tangerang menggunakan output berupa lampu dc LED dengan daya sebesar $12 \mathrm{~W}-12 \mathrm{~V}$, dan pemakaian selama 12 jam/hari. Maka daya yang diperlukan untuk menghidupkan lampu de per tiap harinya adalah sebesar 144 Wh. Berdasarkan perhitungan kapasitas dan kemampuan komponen, untuk dapat menghidupkan lampu dc sebesar 144 
Wh (termasuk cadangan daya) maka diperlukan panel surya $100 \mathrm{Wp}$, battery $35 \mathrm{Ah}$, dan charge control 10 A. Dengan kapasitas lampu dc yang sama tetapi menggunakan panel surya berkapasitas $50 \mathrm{Wp}$, dan battery 65 Ah (konfigurasi berbeda untuk panel surya, dan battery). Dipilihnya lampu dc LED karena lampu LED memiliki usia pemakaian yang panjang yaitu lebih dari 30.000 jam pemakaian.

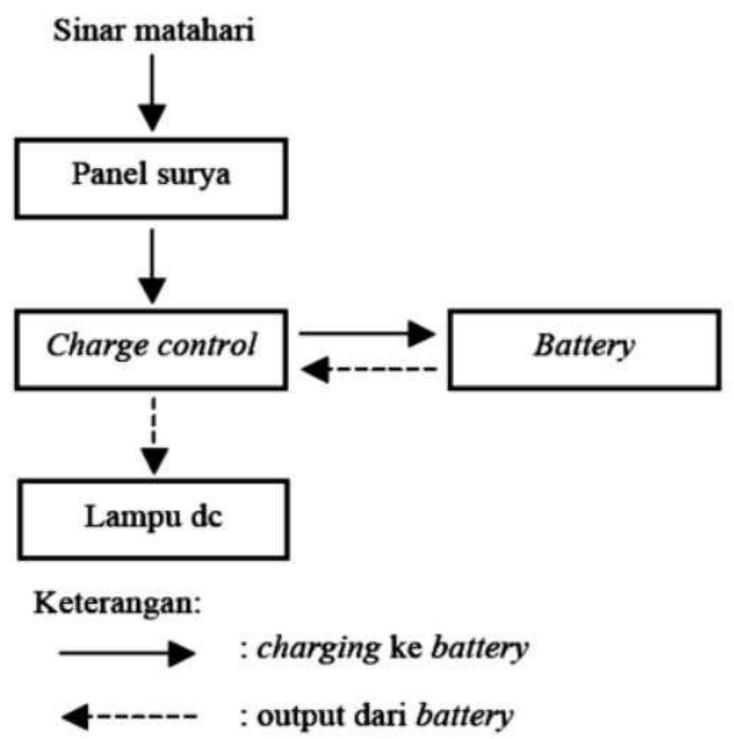

Gambar 6. Prinsip kerja rangkaian lampu PJU berbasis solar system

Prinsip kerja rangkaian lampu PJU berbasis solar system seperti diuraikan dalam Gambar 6. Sinar matahari dikonversi oleh panel surya menjadi energi listrik, dan menjadi inputan daya untuk battery melewati charge control. Proses ini merupakan proses charging battery. Apabila panel surya tidak mendapatkan sinar matahari (malam hari) maka charge control akan meneruskan daya dari battery menuju lampu dc (lampu dc $O N$ ). Sebaliknya apabila panel surya mendapatkan sinar matahari maka charge control akan memutus daya dari battery ke lampu dc (lampu dc $O F F$ ). Kondisi lampu dc $O F F$ memberikan kesempatan kembali proses charging battery.
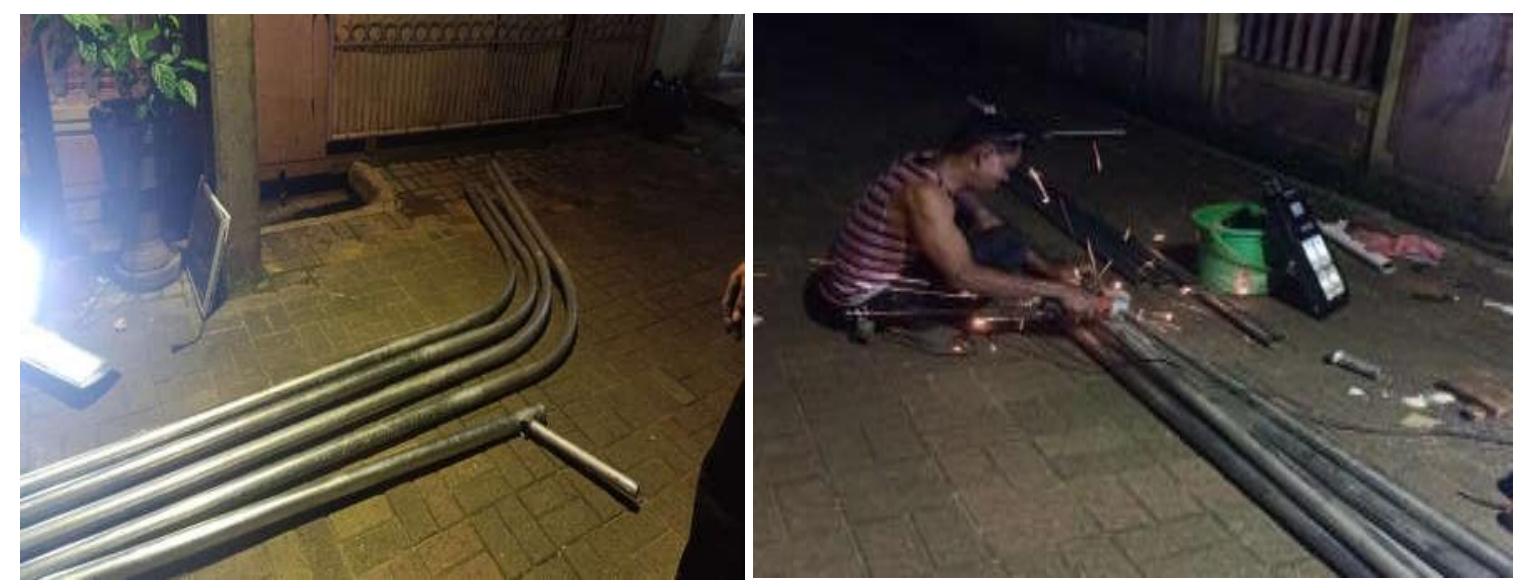

Gambar 7. Perakitan Tiang Lampu PJU tenaga surya 


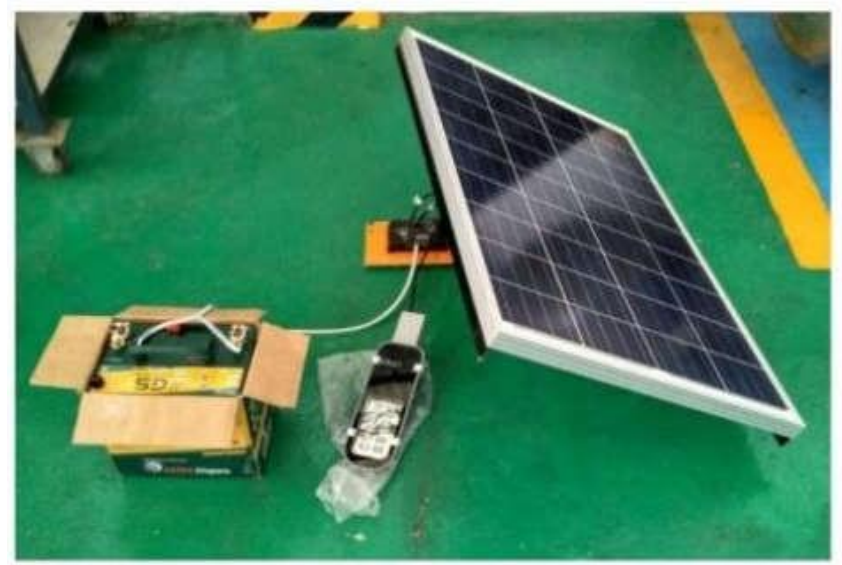

(1) Pengujian kondisi siang hari

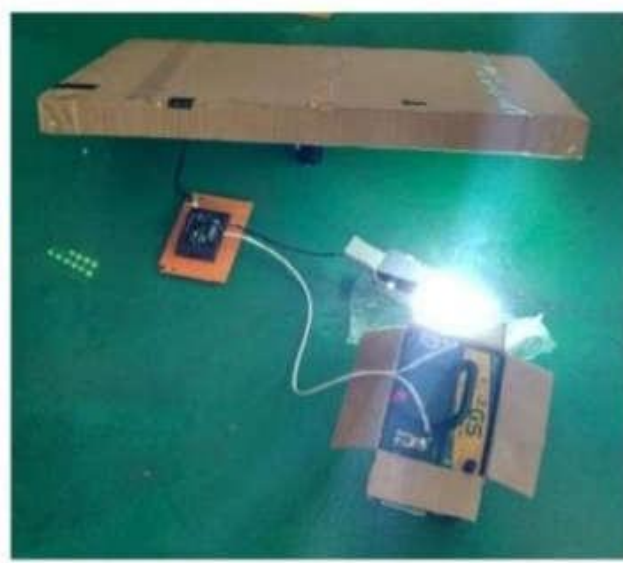

(2) Pengujian kondisi malam hari

Gambar 8. Proses pengujian komponen lampu PJU berbasis solar system

Tiang lampu PJU beserta komponen-komponennya yang telah dibuat, dirakit, dan dilakukan pengujian, selanjutnya dibawa ke titik lokasi yang akan dipasang di Lapangan Olah Raga Warga RT 002/05 BTN Cantiga Petir Cipondoh Tangerang. Bersama-sama dengan masyarakat melakukan pemasangan akhir, dan disertai dengan pendampingan teknis mengenai merawat lampu lampu PJU berbasis solar system. Tujuan kegiatan ini adalah agar masyarakat mampu melakukan perbaikan dan perawatan terhadap lampu PJU secara mandiri. Gambar 9 menunjukkan kegiatan pelaksanaan pemasangan lampu PJU berbasis solar system bersama masyarakat Warga RT 002/05 BTN Cantiga Petir Cipondoh Tangerang.
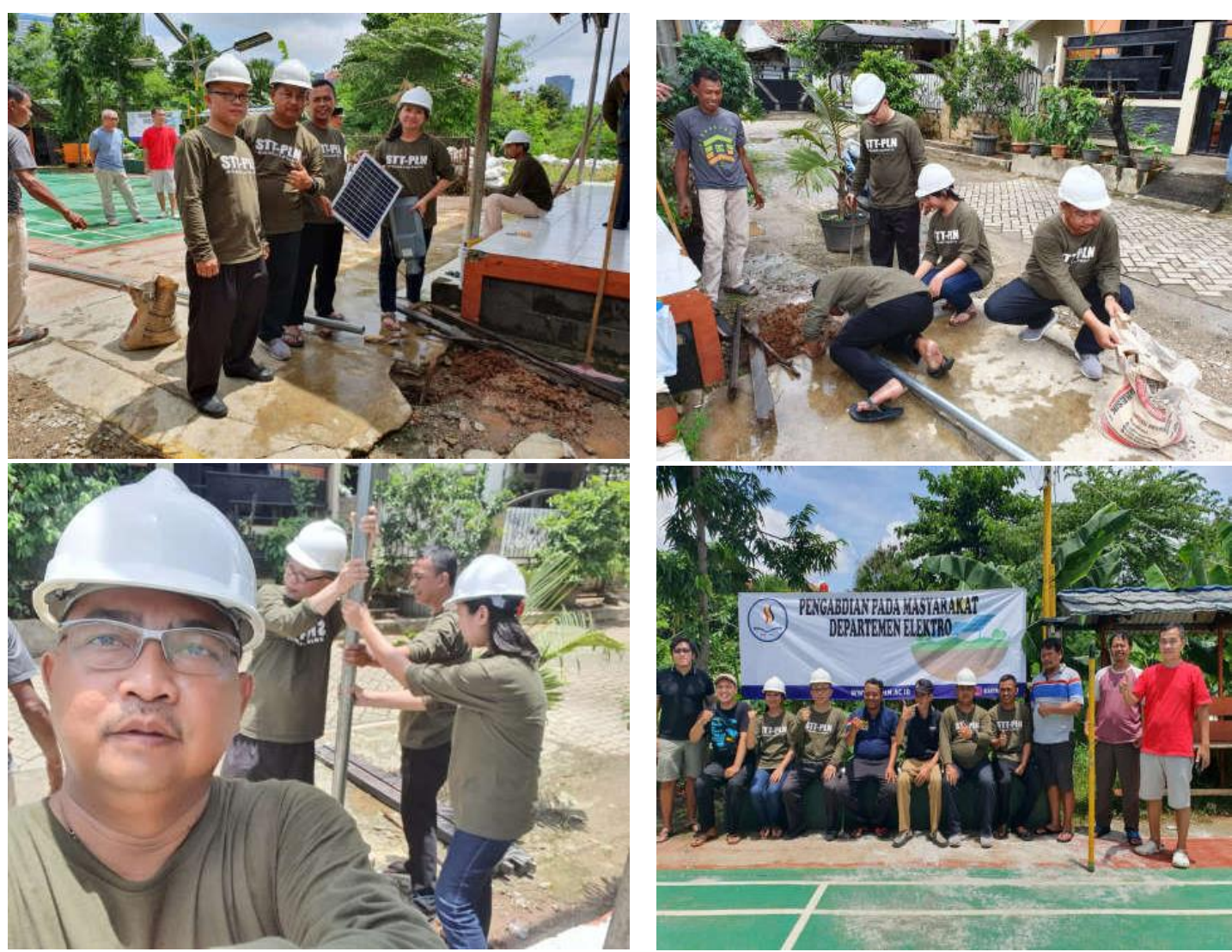

Gambar 9. Pelaksanaan pemasangan Lampu PJU tenaga surya 
Lampu-lampu PJU berbasis solar system yang telah dipasang di lingkungan Warga RT 002/05 BTN Cantiga Petir Cipondoh Tangerang dilakukan monitoring pada kondisi malam hari.

Monitoring ini bertujuan untuk memastikan bahwa lampu PJU yang telah dipasang dapat bekerja dengan baik. Berdasarkan Gambar 10 terlihat bahwa kinerja, dan hasil pencahayaan dari lampu PJU berbasis solar system bekerja dengan baik.

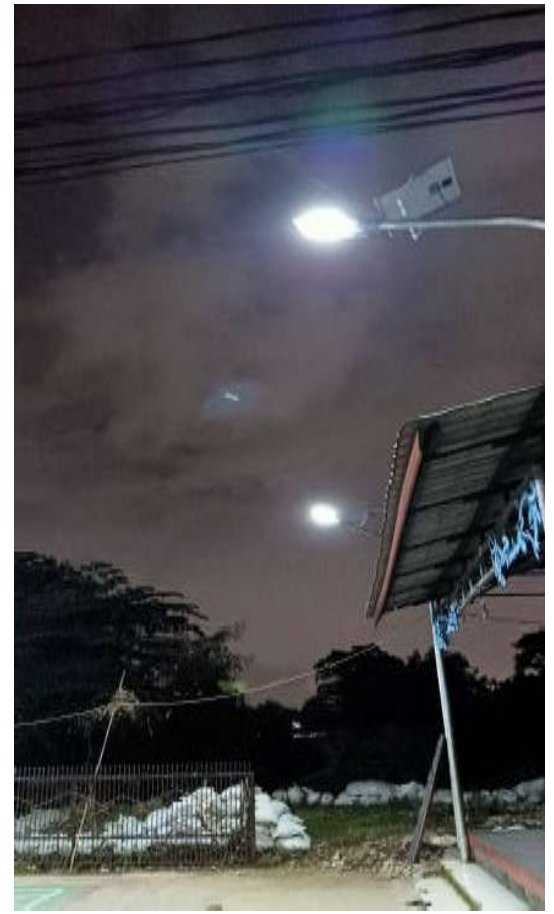

Lokasi 1 dan 2

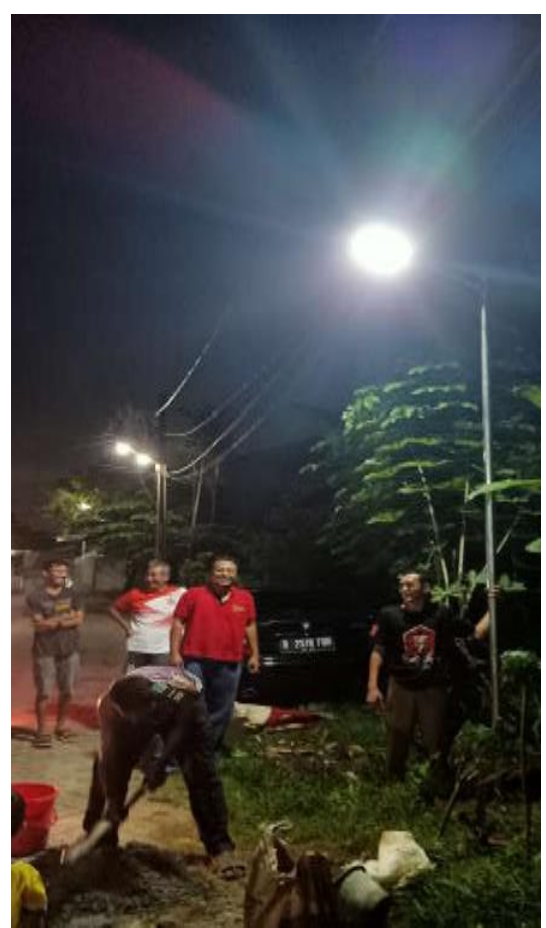

Lokasi 5

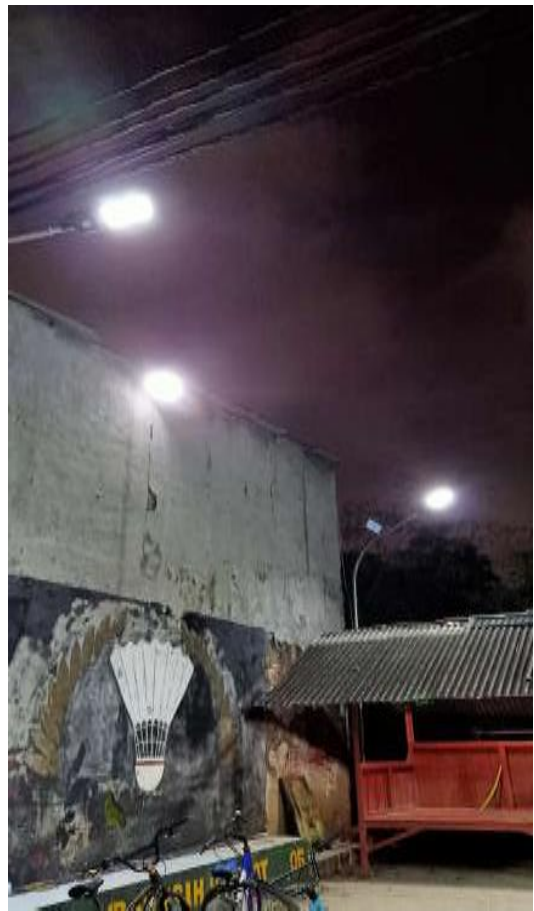

Lokasi 3 dan 4

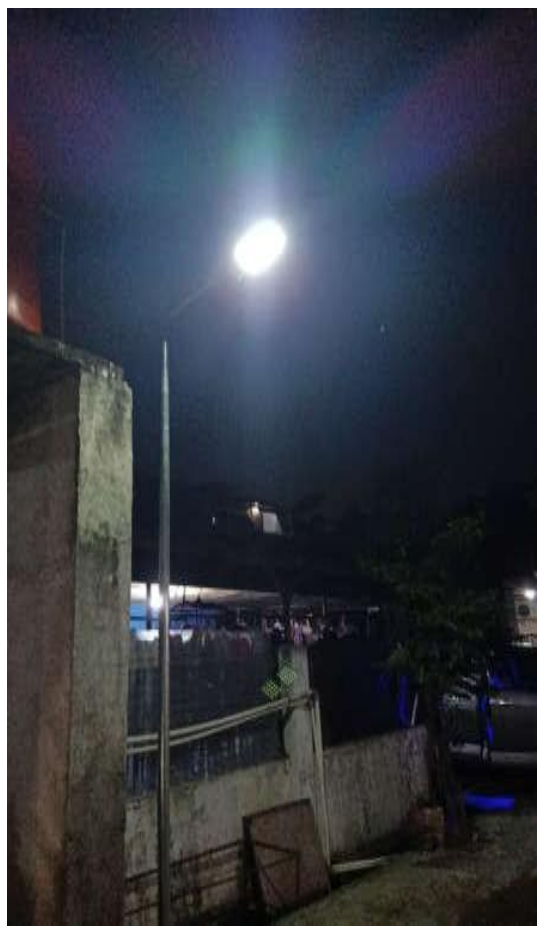

Lokasi 6

Gambar 10. Kinerja lampu PJU berbasis solar system pada kondisi malam hari 
Diakhir kegiatan PKM dilakukan serah terima barang/pekerjaan antara Ketua Tim Pengabdian Kepada Masyarakat (PKM) Institut Teknologi PLN dengan Ketua RT. 002/05 dan RW 05 BTN Cantiga Petir Cipondoh Tangerang, seperti diperlihatkan dalam Gambar 11. Terdapat peluang kedepannya untuk mengembangkan kendali lampu PJU, yaitu dengan menghubungkan ke jaringan internet (internet of things/IoT) sebagai kendali lampu PJU tersebut.

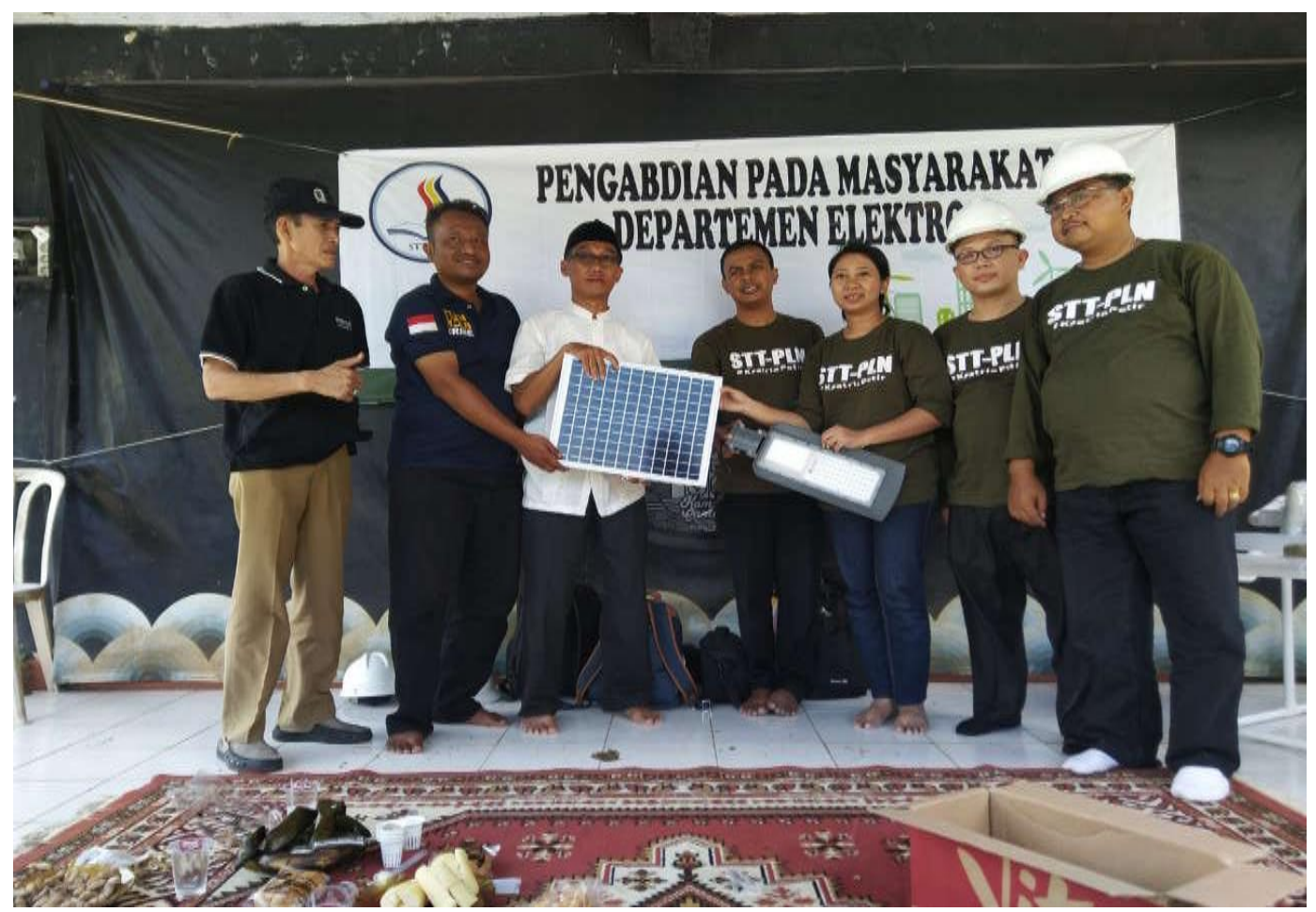

Gambar 11. Kegiatan serah terima barang/pekerjaan kegiatan PKM

\section{KESIMPULAN}

Kegiatan PKM Institut Teknologi PLN Tahun 2019 telah mampu menerapkan teknologi terapan berupa lampu PJU berbasis solar system di lingkungan RT 002/05 BTN Cantiga Petir Cipondoh Tangerang. Luaran/hasil kegiatan PKM ini adalah terjadinya peningkatan fisik lingkungan, yang akan berdampak terhadap, keamanan lingkungan, dan aktivitas masyarakat khususnya pada malam hari.

\section{SARAN}

Kegiatan PKM tersebut terus ditingkatkan dan di lanjutkan dengan melanjuti ditempat lainnya dengan teknologi yang modern untuk mendukung program pemerintah untuk mencapai pemanfaatan energi baru dan terbarukan dengan 2025 tercapai $23 \%$.

\section{UCAPAN TERIMAKASIH}

Penulis mengucapkan terima kasih kepada LPPM Institut Teknologi PLN dan Pusat Penelitian dan Pengkajian Energi Baru dan Terbarukan Institut Teknologi PLN yang telah memberi dukungan yang membantu pelaksanaan PKM dan atau penulisan artikel ini.

\section{DAFTAR PUSTAKA}

[1] Lampiran I Peraturan Presiden Republik Indonesia. (2017). Rencana Umum 
Energi Nasional (Nomor 22).

[2] Heri Suyanto," Technical Analysis Feasibily Study on Smart Microgrid System in Sekolah Tinggi Teknik PLN”, ICENIS 2017, Publisher : E3S Web of Conferences 31, 02011 (2018), doi : https//doi.org/10.1051/e3sconf/20183102011

[3] Suhardi, D. (2014). Prototipe Controller Lampu Penerangan LED (Light Emitting Diode) Independent Bertenaga Surya. Jurnal Gamma, 10 (1), 116-122.

[4] Suriadi, \& Syukri, M (2010). Perencanaan pembangkit listrik tenaga surya (PLTS) terpadu menggunakan software PVSYST pada Komplek Perumahan di Banda Aceh. Jurnal Rekayasa Elektrik, 9 (2), 77-80

[5] Winardi, B., \& Nugroho, A. (2007). Perencanaan Penataan Lampu Penerangan Jalan Umum (LPJU) Sebagai Upaya Efisiensi Tagihan Rekening Listrik Kecamatan Suruh Kabupaten Semarang UPJ Salatiga. Transmisi-Jurnal Teknik Elektro, 9 (2), 138-144 